\title{
Application performance of fuel-powered multi-rotor unmanned aerial vehicles in maize plant protection
}

\author{
Haiyan Zhang ${ }^{1}$, Yubin Lan ${ }^{2,3^{*}}$, Tongyu $\mathrm{Xu}^{1}$, Fenghua $\mathrm{Yu}^{1}$ \\ (1. College of Information and Electrical Engineering, Shenyang Agricultural University, Shenyang 110866, China; \\ 2. National Center for International Collaboration Research on Precision Agricultural Aviation Pesticides, \\ Spraying Technology (NPAAC), South China Agricultural University, Guangzhou 510642, China; \\ 3. College of Electronic Engineering, South China Agricultural University, Guangzhou 510642, China)
}

\begin{abstract}
In recent years, fuel-powered multi-rotor unmanned aerial vehicles (UAV) have been increasingly applied in high-stalk crops, because of their stronger rotor wind field. More and more attention has been paid to UAV application performance in high-stalk crops. Maize is a kind of typical high-stalk crops and it is also one of the main food crops and its planting area ranks third in China, second only to wheat and rice. In this study, a field test was conducted to investigate the application performance in maize crop protection of fuel-powered UAVs and droplets deposition effect on different canopies and leaf positions. The results show that: Due to the assistance of rotor wind field, the coverage rate of droplets in the three maize canopies is all high, but the deposition uniformity in the middle and upper canopy is poor. For the middle and lower leaves of maize, as the height of the leaves position increases, the droplets deposition on the maize leaves increases slowly. For the middle and upper leaves, as the height of the leaves position increases, the droplets deposition increases sharply. Compared with the coverage rate of droplets on the 7th leaf, the coverage rate of the droplets on the 10th maize leaf has increased by $127.12 \%$. For the middle and upper canopy, the coverage rate of droplets in the maize leaf sheath is the highest, followed by the middle leaves, and the lowest tip. For the middle and lower canopy, the coverage rate of the droplets in the middle of the maize leaves is the highest, followed by the sheath, and the lowest tip.
\end{abstract}

Keywords: droplets, coverage rate, maize, fuel-powered UAV

DOI: $10.33440 /$ j.ijpaa.20210402.180

Citation: Zhang H Y, Lan Y B, Xu T Y, Yu F H. Application performance of fuel-powered multi-rotor unmanned aerial vehicles in maize plant protection. Int J Precis Agric Aviat, 2021; 4(2): 36-39.

\section{Introduction}

Maize is one of the main food crops and its planting area ranks third in China, second only to wheat and rice ${ }^{[1]}$. Sheath blight, smut, maize borer, maize aphids, second-generation armyworm, and Spodoptera frugiperda that have invaded China in recent years are the main pests and diseases and will harm maize yield if they happen $^{[1-3]}$. Since maize is a high-stalk crop, the height of the maize in the middle and late growth stages has exceeded the average height of a person, making it difficult for traditional plant protection equipment to enter, affecting the control effect of maize diseases and insect pests, especially large-scale diseases and insect pests happening suddenly, and reducing maize Yield. In addition, the droplets are very difficult for maize and other high-stalk crops to penetrate the crop canopy. Which will restrict the control effect of diseases and insect pests ${ }^{[4]}$.

Compared with the traditional plant protection equipment, such as traditional knapsack sprayers, stretcher sprayers and self-propelled boom sprayers and so on $^{[5-7]}$, plant protection UAVs get rid of the restriction of the ground operation mode, the types of

Received data: 2021-09-10 Accepted data: 2021-10-15

Biographies: Haiyan Zhang, $\mathrm{PhD}$ Student, research interests: Precision Agriculture Spray Technology, Email: 1322366847@qq.com; Tongyu Xu, PhD, Professor, interests: agricultural aerial application technology, Email: 297451949@qq.com. Fenghua Yu, PhD, Associate Processor, interests: agricultural aerial application technology, Email: 344493653@qq.com.

* Corresponding author: Yubin Lan, PhD, Professor, research interests: Precision Agriculture Spray Technology, Mailing Address: South China Agricultural University. Email: ylan@scau.edu.cn. crops (low and high rods Crops, etc.) and the terrain. It has the advantages of high pesticide application efficiency and strong ability to respond to sudden pests and diseases ${ }^{[8,9]}$. Compared with traditional plant protection equipment, the rotor wind field of plant protection UAVs has the characteristics of disturbing object crops canopy, assisting droplet deposition, improving droplet penetration probability, and reducing droplet drift risk ${ }^{[10-13]}$.

Qin $^{[14]}$ used a solution of Rhodamine-B mixed with water in $0.1 \%$ concentration instead of the pesticide to spray maize field, obtained the droplet deposition results by water sensitive paper fixed on maize leaves, analyzed the effect of flight height and swath width of N-3 UAV on the droplet deposition and recommended $7 \mathrm{~m}$ flight height and $7 \mathrm{~m}$ swath width as N-3 UAV operation parameter. $\mathrm{Gao}^{[15]}$ explored the control effect of chlorpyrifos-methyl sprayed by Af-811 UAV on maize borer, and analyzed the effects of the flight height and pesticide concentration on the droplet deposition in the maize canopy, and the control effect of chlorpyrifos-methyl on maize borer. Yang ${ }^{[16]}$ tested the control effect of 3\% phenoxycarb EC sprayed by TXC-8-50-1 eight-rotor plant protection UAV on maize borer at ear stage of maize, and analyzed the effect of flight height, the spray amount of pesticide and droplet evaporation inhibitor on the deposition and distribution of droplet in the maize canopy.

The above research explored the application effects of fuel-powered single-rotor and electric multi-rotor UAV in maize fields, and analyzed the application prospects of the above plant protection UAVs in the field of maize plant protection. The fuel-powered multi-rotor plant protection UAV has stronger rotor wind field and greater assistant effect on droplets. The droplets 
have a better penetration effect on the canopy of high-stalk crops and densely planted crops. Therefore, its application in the plant protection field is gradually increasing, especially in Xinjiang and Northeast China. At present, there are few studies on the operation effect of fuel-powered multi-rotor in the field of maize plant protection. Based on this, this paper uses $200 \mathrm{~g} / \mathrm{L}$ chlorantraniliprole $8 \mathrm{~mL}$ as a spray solution and uses water sensitive paper to test the droplet deposition and penetration effect of 'Dazhuang' fuel-powered multi-rotor plant protection UAV in maize canopy. The test results are expected to provide reference for the evaluation of the application effect of the 'Dazhuang' fuel-powered UAV in the maize field for plant protection operations and the optimization of the Dazhuang UAV structure.

\section{Materials and methods}

\subsection{Spray equipment}

Each rotor of the "Dazhuang” UAV is equipped with an engine to provide power for the rotor alone. Therefore, compared with other plant protection UAVs, the rotor wind field of the Dazhuang UAV is stronger, which is more assistant to droplets deposition. The disturbance to the crop canopy is stronger, which is conducive to the droplets penetrating the crop canopy and depositing to the bottom canopy of the crop.

The maximum pesticide load of the 'Dazhuang' UAV is $60 \mathrm{~kg}$, the longest endurance is 4 hours, the swath width is $8 \mathrm{~m}$, the flight speed is $6 \mathrm{~m} / \mathrm{s}$, the operating height is $4.6 \mathrm{~m}$, and the spray volume is $15 \mathrm{~L} / \mathrm{hm}$.

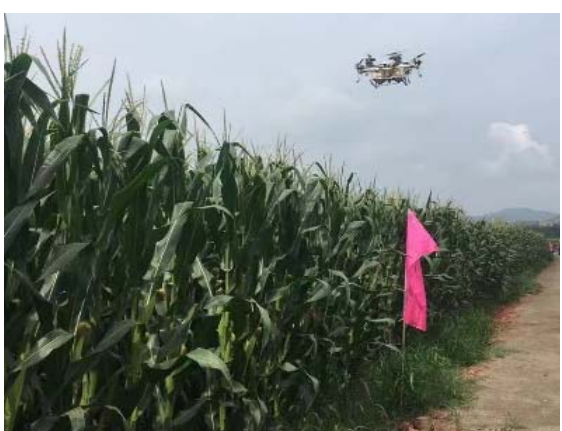

Figure 1 Test mode of UAV

Table 1 The detailed parameters of 'Dazhuang' fuel-powered UAV

\begin{tabular}{lc}
\hline \multicolumn{1}{c}{ Parameters } & Values \\
\hline Fuselage size $/ \mathrm{mm} \times \mathrm{mm} \times \mathrm{mm}$ & $2300 \times 200 \times 900$ \\
Maximum pesticide load $/ \mathrm{kg}$ & 60 \\
the longest endurance $/ \mathrm{h}$ & 4 \\
Flight heitht $/ \mathrm{m}$ & $5-10$ \\
Swath width $/ \mathrm{m}$ & $6-15$ \\
\hline
\end{tabular}

\subsection{Test design and method}

The test was carried out in Tieling, Liaoning Province. The sprayed target was maize at the filling stage. The average height of maize was about $220 \mathrm{~cm}$. Due to the limitation of maize height, the test field was divided by DJI Wizard 4 . The length and width of maize field sprayed in this test were $30 \mathrm{~m}$ and $60 \mathrm{~m}$ respectively.

In order to analyze the deposition performance of droplets in the maize canopy and the impact of the UAV rotor wind field on the penetration probability of droplets, this test arranged a total of 11 sampling points in the test field. Each sampling point arranged three layers water-sensitive paper, the first layer of water-sensitive paper was arranged on the maize leaf $30 \mathrm{~cm}$ from the apex of the ear, the second and third layers were arranged on the leaves $80 \mathrm{~cm}$ and $140 \mathrm{~cm}$ from the first sampling layer respectively, the interval between each sampling point is $1 \mathrm{~m}$. The second row of sampling points were arranged $10 \mathrm{~m}$ away from the first row of sampling points in the same way to obtain the repeat test data, showed as Figure 2a.

The inclination angle of crop leaves affects the retention stability of droplets on crop leaves ${ }^{[17,18]}$. The leaves of maize plants are relatively large, and the inclination angle of the leaves' different parts are significant different. Therefore, the droplets retention potential on maize leaves' different parts are very different. Coupled with the different flexibility of maize leaves' different parts, the maize leaves' different parts response to the rotor wind field of UAV quite different. Which affect significantly the droplet retention and penetration probability on maize canopy ${ }^{[4,19-20]}$. In order to quantify the deposition ability of droplets on maize leaves' different parts, this study arranged two water sensitive papers on each sampling leaf, one at the maize leaf sheath and the other at the middle part of the maize leaf. There is an aging problem in the leaves of maize bottom canopy, so, only a piece of water-sensitive paper is placed on the leaves at the lowest sampling layer of maize. See Figure $2 b$ for details. Then, the average value of the droplet deposition data of the sheath and mid-leaf of each maize leaf was taken to characterize the deposition of droplets on the sheath and mid-leaf of the maize leaf.
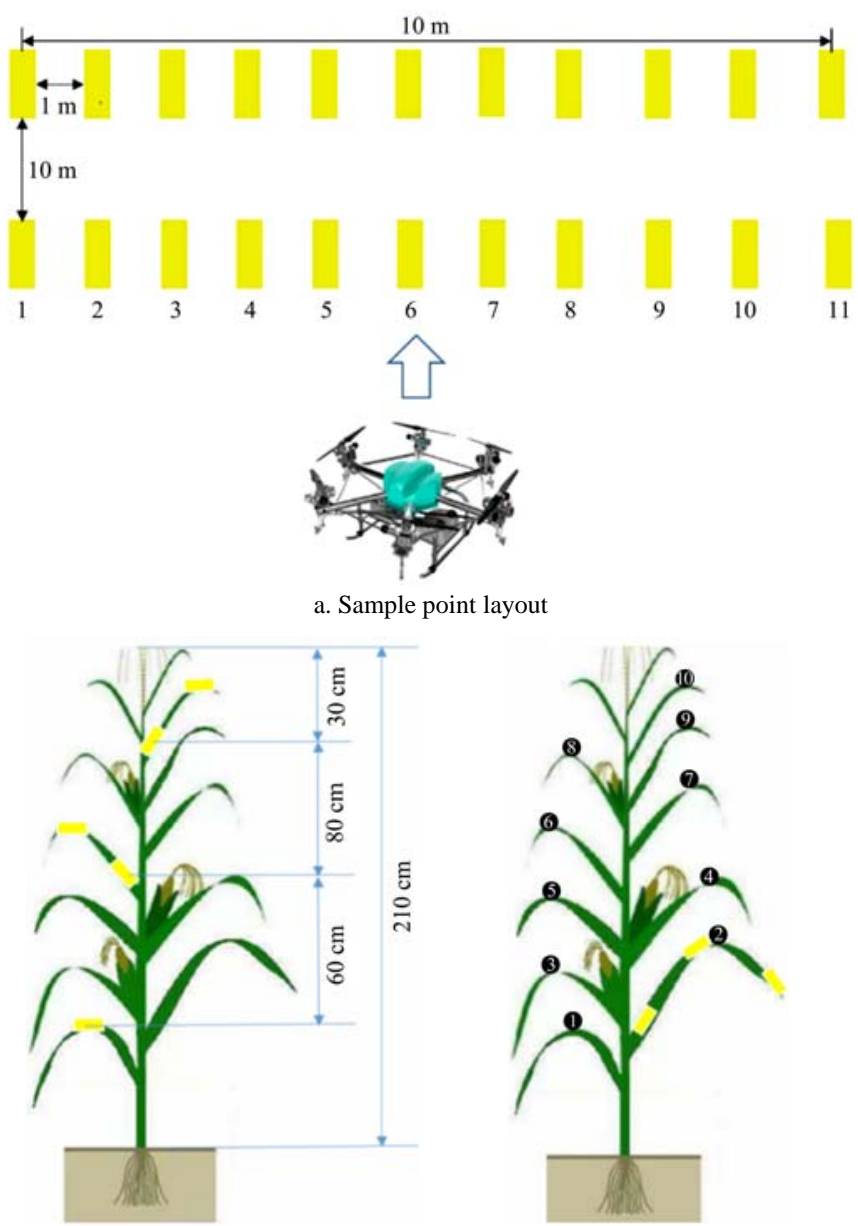

b. The position of water sensitive paper c. The position of water sensitive paper on maize leaves entire maize

Figure 2 Sample point layout

In order to explore the droplets deposition performance on the whole maize plant in detail, a whole maize plant was arranged by water sensitive paper. That is, the sampling water sensitive papers were arranged from the third maize leaf to the penultimate maize 
leaf. There are 10 leaves in total. 3 sheets of water-sensitive paper are arranged on each leaf, the first sheet is arranged at the sheath, the second sheet is arranged in the middle of leaf, and the third sheet is arranged at the tip of the leaf. For detailed information on the layout, see Figure 2c.

During the test, the temperature is $(30 \pm 1)^{\circ} \mathrm{C}$, the wind speed is $0.24 \sim 1.10 \mathrm{~m} / \mathrm{s}$, and the humidity is $50 \% \pm 1 \%$.

\section{Result and analysis}

\subsection{Analysis of droplet deposition on three sampling layers} of maize

Figure 3 shows the coverage rate of droplets sprayed by the 'Dazhuang' plant protection UAV on the upper, middle and lower maize canopies. The coverage rate of droplets on the upper maize canopy is the highest, reaching $5.36 \%$; that of the maize middle canopy reaches $3.32 \%$, and that of the droplet on the lowest maize canopy is the lowest, with a coverage rate of $2.05 \%$. The coverage rate of droplets in the middle and lowest part of the maize plant is about $61.94 \%$ and $38.25 \%$ of the coverage rate of droplets in the upper part of the maize plant.

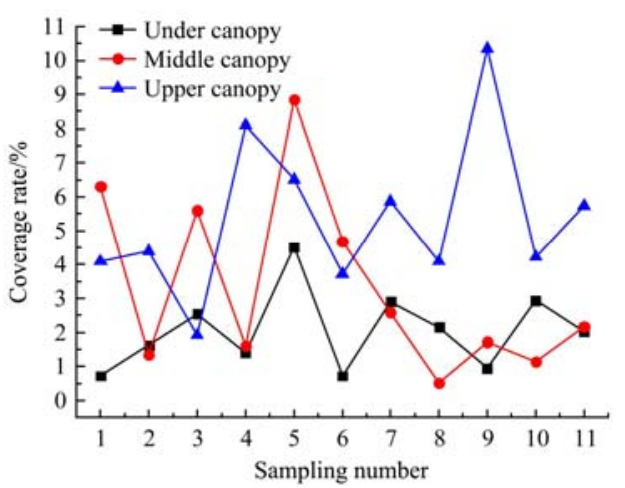

Figure 3 Distribution of droplets deposition in maize 3 canopies

In addition, the coefficient of variation of the coverage rate of droplets at the upper and middle maize sampling layers is higher than $50 \%$, which indicates that the deposition uniformity of droplets in the middle and upper part of the maize is relatively poor. The reason for this phenomenon may be that each rotor of the "Dazhuang" plant protection UAV is equipped with an engine which make the effective rotor wind field be enhanced and the complexity of the coupling wind field between the rotors be increased.

Figure 4 depicts the droplets deposition on the sheath and the middle part of the maize leaf. Based on Figure 4, the coverage rate of the droplet on the maize leaf sheath is slightly higher than that of the droplet on the middle part of the maize leaf. And the deposition uniformity of the droplets in the maize leaf sheath is slightly better than that of the droplets in the middle of the maize leaf, which is different from the conventional droplet deposition trend. The possible reason for this result is that the flexibility of the sheath of the maize leaf is poor, and the effect of the rotor wind field disturbance is less, and the probability of droplets deposition on the sheath of the maize is relatively higher. The flexibility of the middle part of the maize leaf is better, and the rotor wind field disturbance has a great influence on the middle part of maize leaf. Due to the violent sway of the leaves, the probability of droplets colliding with the leaves and eventually deposition on the blades is greatly reduced. Thereby reducing the droplets deposition in the middle of the maize leaves, and increasing the difference in the result of the droplet deposition in the middle of the maize leaf.

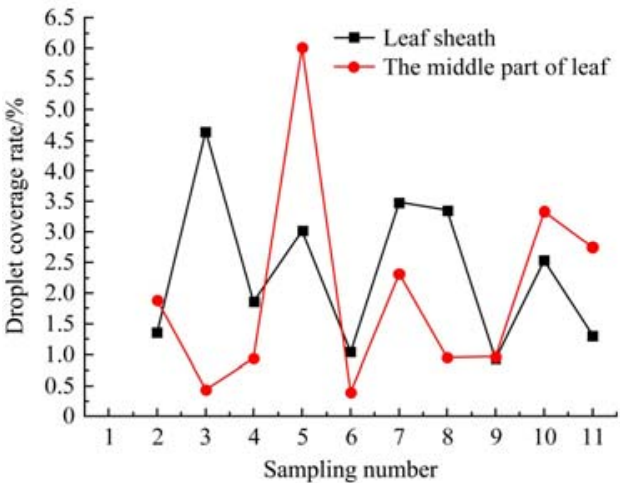

Figure 4 Distribution of droplets deposition in the sheath and middle part maize leaves

\subsection{Analysis of the droplet deposition on the whole maize}

Figure 5 depicts the droplets deposition on the entire maize leaf. It can be seen from Fig.5 that as the position of the leaf rises, the coverage rate of the droplets on the maize leaves increases. From the first leaf to the sixth leaf at the bottom, the coverage rate of droplets on the leaves increased slightly with the increase of leaf position height, and the average coverage rate of droplets was $0.80 \%$. The volume median diameter of the droplets fluctuates between 221 349 um. From the seventh leaf, the coverage rate of droplets enhanced sharply with the increase of leaf position height. Compared with the coverage rate of droplets on the seventh leaf, the coverage rate of droplets on the 10th maize leaf increased by $127.12 \%$

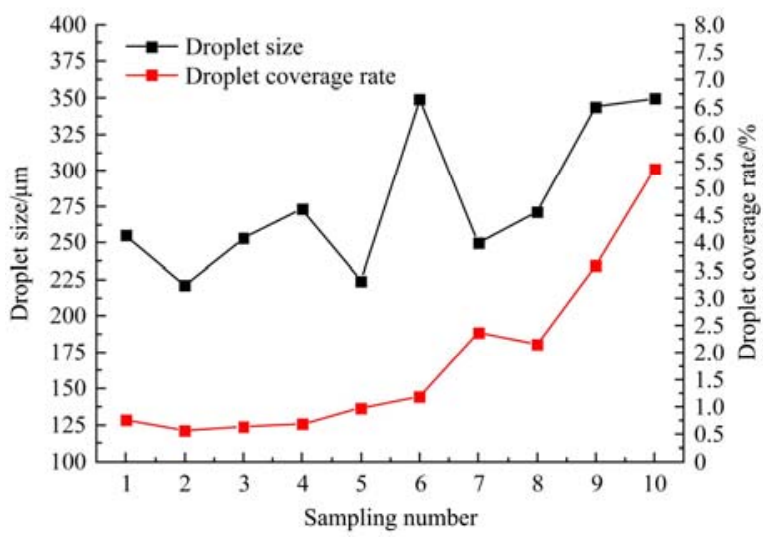

Figure 5 Distribution of droplets deposition on entire maize

Figure 6 depicts the coverage rate of droplets on the tip, middle and sheath of 10 maize leaves. It can be seen from Figure 6 that the droplet coverage rate is the highest in the middle part of leaves for lower maize leaves (1-6 leaves from maize bottom), the average coverage rate is $1.03 \%$; the leaf sheath is second, the coverage rate reaches $1.01 \%$. The droplet coverage rate at the tip of the leaf, the coverage rate is the lowest, with a coverage rate of $0.57 \%$. For the upper part of maize (7-10 leaves), the coverage rate of droplets on the sheath of maize leaves is the highest, with a coverage rate of $4.12 \%$. The coverage rate on the middle of maize is the second, with a coverage rate of $3.28 \%$. The coverage rate at the tip of the leaf is the lowest, the coverage rate was $2.69 \%$.

The possible reason for this phenomenon is that the rotor wind field of the 'Dazhuang' plant protection UAV is too strong and disturbs the middle and upper maize canopy too much. Therefore, the leaf tip with the highest degree of freedom is affected by the rotor wind field. Too intense disturbance for leaf tip results in the worst droplet coverage, while the leaf sheath has the lowest flexibility and is less disturbed by the rotor wind field. Therefore, 
in the middle and upper maize leaves, the droplet coverage on the maize leaf sheath is the highest. However, blocked by maize plants, when the UAV rotor wind field reaches the middle and lower part of the maize, the wind field weakens a lot, and the disturbance to the maize stalks and leaves is weak. Therefore, the effective area of maize leaf plays a more important role in intercepting droplets. So, on the middle and lower leaves of maize, the coverage rate of droplets in the middle part of the maize leaves is the highest, followed by the sheath, and the coverage rate of droplets in the tip of the leaf is the lowest.

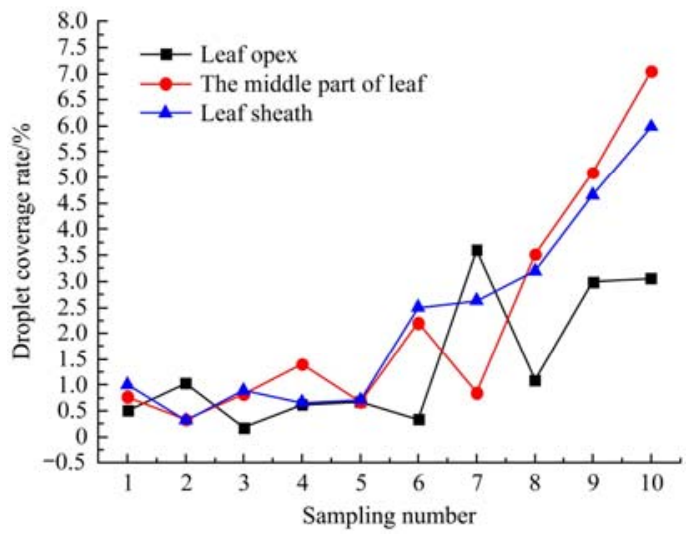

Figure 6 Distribution of droplets deposition in 3 parts of a leaf for entire maize

\section{Conclusions}

Water-sensitive paper was used as an alternative target to test the deposition performance of droplets sprayed by the "Dazhuang" fuel-powered multi-rotor plant protection UAV on different maize canopies and different position leaves, and analyzed the impact of the rotor wind field on the penetration effect of the droplets in the maize canopy and the deposition rate and uniformity of the droplets on different parts of the maize leaves. The conclusion is as follows:

1) Due to the assistance of the rotor wind field of the 'Dazhuang' plant protection UAV, the coverage rate of droplets in the three maize canopies is high, but the deposition uniformity in the middle and upper canopy is poor.

2) For the middle and lower leaves of maize, as the height of the leaf position increases, the amount of droplets deposited on the maize leaves increases, but the increase is not high. For the middle and upper leaves, as the height of the leaves position increases, the droplets deposition on the maize leaves increase sharply. Compared with the coverage rate of droplets on the 7th leaf, the coverage rate of the droplets on the 10th maize leaf has increased by $127.12 \%$.

3) For the middle and upper canopy, the coverage rate of droplets in the maize leaf sheath is the highest, followed by the middle leaves, and the leaf tip is the lowest. For the middle and lower canopy, the coverage rate of the droplets in the middle of the maize leaves is the highest, followed by the sheath. The tip of the leaf is the lowest.

\section{[References]}

[1] Han B S, Tong L H, Chen X L. Occurrence characteristics and control measures of maize diseases and insect pests. Journal of Modern Agricultural Science and Technology, 2021(8): 80-81.

[2] Zheng $\mathrm{X} \mathrm{H}$. High-yield maize planting techniques and common pest control measures. Journal of Agricultural Technology and Equipment, 2021(3): 154-156

[3] Ming S L, Jiang S f. Analysis on the control technology of maize diseases and pests. Journal of Henan Agricultural, 2020(17): 30-31

[4] Zhang H Y, Lan Y B, Wen S, et al. Research progress in rotor airflow model of plant protection UAV and droplet motion mechanism. Transactions of the Chinese Society of Agricultural Engineering (Transactions of the CSAE), 2020, 36(22): 1-12. doi: 10.11975/ j.issn.1002-6819.2020.22.001

[5] Xue X Y, Gao C Y, Fu X M, et al. R \& D of high-efficiency, wide-coverage and long-range combined spray gun. Transactions of the Chinese Society of Agricultural Engineering (Transactions of the CSAE), 2001, 17(4): 70-74. doi: 10.3321/j.issn:1002-6819.2001.04.016

[6] Liu W, Wang X C, Ding W M, et al. Design and characteristics analysis of variable spraying control system for knapsack sprayer. Transactions of the Chinese Society of Agricultural Engineering (Transactions of the CSAE), 2012, 28(9): 16-21. doi: 10.3969/j.issn.1002-6819.2012.09.003

[7] Zhang T. Experimental Study and CFD Simulation of Air-assisted System on Super-high Clearance Boom Sprayer. Beijing: Chinese Academy of Agricultural Mechanization Sciences, 2012.

[8] Zhang D Y, Lan Y B, Chen L P, et al. Current status and future trends of agricultural aerial spraying technology in China. Transactions of the Chinese Society of Agricultural Engineering, 2014, 45(10): 53-59. doi: 10.6041/j.issn.1000-1298.2014.10.009

[9] Xue X Y, Tu K, Qin W C, et al. Drift and deposition of ultra-low altitude and low volume application in paddy field. International Journal of Agricultural and Biological Engineering, 2014(7): 23-28. doi: 10.3965/ j.ijabe.20140704.003

[10] Zhang H Y, Lan Y B, Wen S, et al. Operational effects of unmanned helicopters for pesticide spraying in rice field. Journal of South China Agricultural University, 2019, 40(1): 116-124. doi: 10.7671/j.issn.1001411X.201802028

[11] Yang F B, Xue X Y, Cai C, et al. Effect of down wash airflow in hover on droplet motion law for multi-rotor unmanned plant protection machine. Transactions of the Chinese Society of Agricultural Engineering (Transactions of the CSAE), 2018, 34(2): 64-73. doi: 10.11975/ j.issn.1002-6819.2018.02.009.

[12] Wen S, Han J, Lan Y B, et al. Influence of wing tip vortex on drift of single rotor plant protection unmanned aerial vehicle. Transactions of the Chinese Society for Agricultural Machinery, 2018, 49(8):127-137. doi: 10.6041/j.issn.1000-1298.2018.08.015

[13] Shen W, Hu J, Ning Z H, et al. Numerical analysis and validation of spray distributions disturbed by quad-rotor drone wake at different flight speeds. Computers and Electronics in Agriculture, 2019. doi: https://doi.org/10.1016/j.compag.2019.105036

[14] Qin W C, Xue X Y, Zhou L X, et al. Effects of spraying parameters of unmanned aerial vehicle on droplets deposition distribution of maize canopies. Transactions of the Chinese Society of Agricultural Engineering (Transactions of the CSAE), 2014, 30(5): 50-56. doi: 10.3969/j.issn.1002-6819.2014.05.007

[15] Gao Y Y, Zhang Y T, Zhao Y C, et al. Primary studies on spray droplet distribution and control effects of aerial spraying using unmanned aerial vehicle (UAV) against the maize borer. Journal of Plant Protection, 2013, 39(2): 152-157. doi: 10.3969/j.issn.0529-1542.2013.03.02.031

[16] Yang S, Wang G B, Yang D B, et al. Preliminary study on low-altitude spraying of Fenoxycarb by UAV to control Asian maize borer. Journal of Botany, 2015, 35(2): 59-62.

[17] Yang X W, Dai M L, Song J L, et al. Effect of droplet size, leaf characteristics and angle on pesticide deposition. Transactions of the CSAE, 2012, 28(3): 70-73. doi: 10.3969/j.issn.1002-6819.2012.03.013

[18] Dorr G J, Wang S, Mayo L C, et al. Impaction of spray droplets on leaves: Influence of formulation and leaf character on shatter, bounce and adhesion. Experiments in Fluids, 2015, 56(7): 1-17. doi: 10.1007/s00348-0152012-9

[19] Song J L, Wang B, Zeng A J, et al. Deposition part analysis and microscopic test of spray droplets on rice leaves. 2013, 44(04): 54-58+76. doi: 10.6041/j.issn.1000-1298.2013.01.010

[20] Ding W Long, Jin M J, Luo L F, et al. Behavior analysis of spray droplet interacting with plant leaves based on virtual model. Transactions of the Chinese Society of Agricultural Engineering (Transactions of the CSAE), 2017, 33(14): 48-56. doi: 10.11975/j.issn.1002-6819.2017.14.006 